\title{
IMPLEMENTASI PROGRAM ASI EKSKLUSIF DI PUSKESMAS ALAI KECAMATAN TEBING TINGGI BARAT KABUPATEN KEPULAUAN MERANTI
}

\author{
Welly Sando $^{1}$, Dami Yanthi ${ }^{2}$, M.Dedi Widodo ${ }^{3}$, Tengku Khairani ${ }^{4}$ \\ S1 Kesehatan Masyarakat, STIKes Hang Tuah Pekanbaru \\ Welly.agir81@gmail.com¹, dediwidodo89@gmail.com²
}

\begin{abstract}
Implementation is the implementation of laws in which various actors, organizations, procedures, and techniques work together to carry out policies in an effort to achieve policy objectives or policy programs. Exclusive breastfeeding coverage The Meranti Islands District Health Office experienced the lowest exclusive breastfeeding coverage in 2019, namely Alai Community Health Center, which is $25 \%$ where the achievement of the exclusive Breastfeeding Program in Meranti Islands Regency in 2019 is 50\% and still far from the national target of $80 \%$. This study aims to determine the implementation of the exclusive breastfeeding program at Alai Public Health Center, Tebing Tinggi Barat District, Meranti Islands Regency in 2020. This type of qualitative research uses observational research. When the research was conducted in June-August at the Alai Public Health Center, Tebing Tinggi Barat District, Meranti Islands Regency. The research subjects were the head of the puskesmas (IK1), pregnant women (IU1), PJ KIA (IP1), and posyandu cadres (IP2). Data analysis is used by systematically arranging the interview guidelines, then processing the data, data from observations are identified to describe each variable, a summary will be presented in narrative form. The results of this study indicate that the policies in the exclusive breastfeeding program have been implemented but the coverage of exclusive breastfeeding is still low because many pregnant women do not follow the recommendations that have been given by health workers in counseling such as the benefits of breastfeeding. It can be concluded that health workers in the policy of the exclusive breastfeeding program provide counseling to pregnant women and approach pregnant women in order to achieve an exclusive breastfeeding program. It is recommended that the head of the Alai Community
\end{abstract}

Keywords : Exclusive ASI Program, Health Workers, Infrastructure Facilities, Policies

\begin{abstract}
ABSTRAK
Implementasi merupakan kegiatan yang dilakukan melalui perencanaan dan mengacu pada aturan tertentu untuk mencapai tujuan kegiatan tersebut. Cakupan ekslusif Dinas Kesehatan Kabupaten Kepulauan Meranti mengalami cakupan Air Susu Ibu eksklusif terendah terdapat pada tahun 2019 yaitu Puskesmas Alai yaitu sebesar 25\% dimana pencapaian program Air Susu Ibu eksklusif Kabupaten Kepulauan Meranti dalam tahun 2019 yaitu 50\% dan masih jauh dari target nasional sebesar $80 \%$. Penelitian ini bertujuan untuk mengetahui Implementasi Program ASI Eksklusif di Puskesmas Alai Kecamatan Tebing Tinggi Barat Kabupaten Kepulauan Meranti Tahun 2020. Jenis penelitian kualitatif dengan menggunakan observasional. Waktu penelitian dilakukan pada bulan Juni-Agustus tahun 2020 di Puskesmas Alai Kecamatan Tebing Tinggi Barat Kabupaten Kepulauan Meranti. Subjek penelitian yaitu kepala puskesmas (IK1), ibu hamil (IU1), PJ KIA (IP1), dan kader posyandu (IP2). Analisis data yang digunakan dengan cara mengatur secara sistematis pedoman wawancara, selanjutnya memproses data, data dari observasi diidentifikasi untuk menggambarkan masing-masing variabel, ringkasan akan disajikan dalam bentuk narasi. Hasil penelitian ini menunjukkan kebijakan dalam program ASI eksklusif sudah dijalankan tetapi masih rendah cakupan ASI eksklusif karena ibu hamil banyak yang tidak mengikuti anjuran yang telah disampaikan tenaga kesehatan dalam penyuluhan seperti manfaat ASI. Dapat disimpulkan tenaga kesehatan dalam kebijakan program ASI eksklusif memberikan konseling pada ibu hamil dan melakukan pendekatan dengan ibu hamil agar tercapai program ASI eksklusif. Disarankan pada Kepala Puskesmas Alai hendaknya pelaksanaan kebijakan ASI eksklusif sebaiknya dilakukan sesuai Peraturan Pemerintah dengan menyediakan ruang laktasi, melakukan pengawasan terhadap
\end{abstract}


distribusi susu formula bagi bayi 0-6 bulan, dan diharapkan semua pihak dapat mendukung pelaksanaannya.

Kata Kunci : Kebijakan, Program ASI Eksklusif, Sarana Prasarana, Tenaga Kesehatan

\section{PENDAHULUAN}

Proses menyusui merupakan hal yang terpenting bagi perempuan. Dalam bidang kesehatan, dikenal adanya pendekatan continuum of care. Pendekatan continuum of care khususnya dalam layanan kesehatan bagi ibu dan anak yang memfokuskan diri pada layanan kesehatan pada 1000 hari pertama kehidupan . ASI secara eksklusif merupakan makanan terbaik bagi bayi yang diberikan mulai saat kelahiran sampai 6 bulan tanpa tambahan makanan apapun. Program ASI Eksklusif telah dicanangkan pemerintah sejak tahun 1980. Namun pada tahun 1990 program ASI Eksklusif pertama kali disosialisasikan secara luas di Indonesia (Riyadi,2015)

ASI eksklusif merupakan pilihan asupan nutrisi yang sangat baik bagi bayi. Namun masih banyak ibu yang salah mengartikan pengertian dari ASI eksklusif, dimana mereka biasanya hanya memfokuskan bahwa ASI eksklusif hanya tidak memperbolehkan pemberian makanan tambahan saja. Menurut Peraturan Pemerintah nomor 33 tahun 2012 tentang pemberian ASI eksklusif, ASI eksklusif adalah ASI yang diberikan kepada bayi sejak dilahirkan selama 6 (enam) bulan, tanpa menambahkan atau mengganti dengan makanan atau minuman lain (Prasetyono, 2019).

Upaya untuk mendukung peningkatan pemberian ASI eksklusif dapat dilihat dari telah dikeluarkannya berbagai pengakuan atau kesepakatan baik yang bersifat global maupun nasional yang bertujuan melindungi, mempromosi, dan mendukung pemberian ASI. Dengan demikian, diharapkan setiap ibu di seluruh dunia dapat melaksanakan pemberian ASI dan setiap bayi diseluruh dunia memperoleh haknya mendapat ASI. Sesuai dengan tujuan Sustainable Development Goals (SDGs) ke-3 target ke-2 yaitu pada tahun 2030, mengakhiri kematian bayi dan balita yang dapat dicegah, dengan seluruh negara berusaha menurunkan Angka Kematian Neonatal setidaknya hingga 12 per 1.000 Kelahiran Hidup (Depkes, 2016).

Negara Indonesia sudah memiliki Undang-Undang dan juga Peraturan Pemerintah yang mengatur pemberian ASI Eksklusif. Hal ini ditujukan untuk meningkatkan pemberian ASI Eksklusif oleh ibu-ibu yang ada di Indonesia. Pemberian ASI diatur didalam Peraturan pemerintah Republik Indonesia nomor 33 tahun 2012 tentang pemberian Air Susu Ibu ekslusif. Pasal 6 menegaskan bahwa setiap ibu yang melahirkan harus memberikan ASI ekslusif kepada bayi yang dilahirkannya. Dapat disimpulkan bahwa menurut Peraturan Pemerintah nomor 33 tahun 2012 pasal 6 target capaian ASI Eksklusif di Indonesia adalah 100\%. Tidak hanya sampai di sana, UndangUndang Republik Indonesia Nomor 36 tahun 2009 tentang Kesehatan pasal 128 ayat 1 yang berbunyi: Setiap bayi berhak mendapatkan asir susu ibu ekslusif sejak dilahirkan selama 6 (enam) bulan, kecuali atas indikasi medis. Selanjutnya pelayanan yang mendukung pemberian Air susu ibu ekslusif juga tercantum pada peraturan pemerintah Republik Indonesia Nomor 61 tahun 2014 tentang kesehatan reproduksi pasal 17 ayat 1 . ASI Ekslusif juga termasuk kedalam Intervensi spesifik dalam kegiatan atau tindakan untuk mensukseskan program pemerintah 1000 hari pertama kehidupan. Yang memprioritaskan memperbaiki gizi masyarakat Indonesia (Astuti, 2016). 
United Nation International Children's Emergency Fund (UNICEF) menyebutkan bahwa anak-anak yang mendapat ASI eksklusif 14 kali lebihmungkin untuk bertahan hidup dalam enam bulan pertama kehidupan dibandingkan anak yang tidak disusui. Menyusui juga mendukung kemampuan seorang anak untuk belajar dan membantu mencegah obesitas dan penyakit kronis dikemudian hari. Banyaknya manfaat ASI Eksklusif baik bagi ibu, bayi, keluarga maupun negara seharusnya menjadi pemicu bagi ibu- ibu yang memiliki bayi yang berumur 0-3 bulan untuk hanya memberikan ASI saja tanpa tambahan apapun. Namun pada kenyataannya capaian Angka Eksklusif baik di dunia maupun Indonesia, masih sangat jauh dari yang diharapkan. Rendahnya cakupan pencapaian pemberian ASI Eksklusif dikarenakan masih kurangnya dukungan dan tanggung jawab global dalam menyatukan komitmen dan prioritas yang lebih tinggi guna menghasilkan kebijakan yang lebih besar serta mengikut sertakan dunia dalam mempromosikan ASI Eksklusif (Depkes, 2015).

Berdasarkan penelitian febrihartanty (2018) menyatakan banyak faktor yang mempengaruhi pemberian ASI eksklusif pada bayi usia 0-6 bulan. Salah satunya ialah air susu ibu tidak keluar. Penyebab air susu tidak keluar juga tidak sedikit, mulai dari stres mental sampai ke penyakit fisik, termasuk malnutrisi. Namun demikian, perilaku tidak menyusui bayi segera setelah lahir (dengan 2 catatan bahwa ibu tidak dalam keadaan terbius dan mengidap penyakit tertentu sehingga tidak memungkinkan untuk menyusui, serta bayi tidak menderita kelainan saluran mulut, saluran napas, atau lahir tidak cukup bulan) terutama dikondisikan oleh pemasaran susu formula, baik melalui iklan maupun memasok langsung produknya ke rumah sakit atau rumah bersalin.

Berdasarkan hasil laporan data Dinas Kesehatan Kabupaten Kepulauan Meranti, angka cakupan ASI eksklusif dari 10 Puskesmas yang ada di Kabupaten Kepulauan Meranti yaitu:

Tabel 1. Cakupan ASI eksklusif di Dinas Kesehatan Kabupaten

\begin{tabular}{llccc}
\hline \multirow{2}{*}{ No } & Puskesmas & \multicolumn{3}{c}{ Tahun } \\
\cline { 3 - 5 } & & 2017 & 2018 & 2019 \\
\hline 1 & Selat Panjang & 14 & 8 & 38 \\
\hline 2 & SungaiTohor & 29 & 51 & 40 \\
\hline 3 & Alah Air & 43 & 23 & 52 \\
\hline 4 & Alai & 17 & 28 & 25 \\
\hline 5 & Tanjung & 54 & 43 & 45 \\
& Samak & & & \\
\hline 6 & Anak Setatah & 54 & 43 & 61 \\
\hline 7 & Kedabu Rapat & 17 & 22 & 33 \\
\hline 8 & Pulau Merbau & 23 & 53 & 34 \\
\hline 9 & Teluk & 27 & 31 & 35 \\
& Belitung & & & \\
\hline 10 & Bandul & 34 & 33 & 42 \\
\hline & Total & $31,2 \%$ & $33,5 \%$ & $40,5 \%$ \\
\hline
\end{tabular}

Berdasarkan tabel 1 diatas, cakupan ASI ekslusif Dinas Kesehatan Kabupaten Kepulauan Meranti dimana yang mengalami cakupan ASI eksklusif terendah terdapat pada tahun 2019 yaitu Puskesmas Alai yaitu sebesar $25 \%$ dimana pencapaian program ASI eksklusif Kabupaten Kepulauan Meranti dalam tahun 2019 yaitu $50 \%$ dan masih jauh dari target nasional sebesar $80 \%$ (Profil Dinkes Kabupaten Kepulauan Meranti, 2019).

Puskesmas alai merupakan puskesmas yang terletak di Kabupaten Kepulauan Meranti, berdasarkan hasil wawancara dengan PJ KIA Puskesmas Alai selama ini program ASI Eksklusif hanya dilakukan dengan memberikan konseling atau edukasi hanya pada saat kelas ibu hamil dan posyandu yang diadakan setiap bulannya, IMD (Inisiasi Menyusui Dini), serta pencatatan dan pelaporan, namun ada beberapa masalah yang dihadapi dalam pelaksanaan program ASI eksklusif yaitu keterbatasan media seperti poster alat peraga untuk penyuluhan, kurangnya tenaga kesehatan yang trampil dan tidak pernah mengikuti pelatihan khusus. Peneliti juga melihat tidak ada penyuluhan khusus terkait dengan 
pemberian ASI eksklusif pada saat posyandu, sehingga ibu-ibu banyak yang tidak memahami ASI eksklusif dan manfaatnya secara detail karena petugas kesehatan tidak memberi tahu secara jelas dan tidak ada menjelaskan menggunakan alat peraga. Hal tersebut berpengaruh terhadap rendahnya pencapaian pemberian ASI eksklusif di Puskesmas Alai.

Berdasarkan survei pendahuluan di posyandu terhadap ibu bayi, bahwa ketidakberhasilan pemberian ASI eksklusif dikarenakan ibu sibuk dengan bekerja, mengalami stres, kelelahan dan ada yang mengalami mastitis sehingga ASI tidak keluar. Kemudian sebagian dari ibu bayi jarang menghadiri posyandu sehingga tidak mengetahui apa itu ASI eksklusif, dan ada 1 bayi hanya mendapatkan ASI selama 1 bulan karena dengan alasan ASI ibu tidak keluar dengan lancar sehingga bayi diberikan susu formula. Hal inilah yang menyebabkan program ASI eksklusif belum sesuai pencapaian target nasional yakni masih dibawah $80 \%$ dikarenakan kurangnya ketersediaan sarana prasarana, dana, tenaga, serta sosialisasi ASI eksklusif dipaketkan dengan sosialisasi kesehatan yang lain.

\section{METODE}

Jenis penelitian yang digunakan dalam penelitian ini adalah kualitatif dengan desain deskriptif kualitatif dilakukan di empat posyandu lansia yang ada di wilayah kerja Puskesmas Alai Kecamatan Tebing Tinggi Barat Kabupaten kepulauan meranti. Waktu penelitian ini dilakukan pada bulan Juni-Agustus tahun 2020. Subjek dipilih sesuai dengan prinsip kesesuaian dan kecukupan, dimana kriteria informan yang dipilih dalam penelitian ini bersedia diwawancarai, mengetahui permasalahan dengan jelas dan dapat dipercaya untuk menjadi sumber data yang baik. Subjek penelitian ini yaitu, Kepala Puskesmas 1 orang, Ibu Hamil 2 orang, kader PJ KIA 1 orang, dan Kader Posyandu 1 orang.

\section{HASIL}

\section{Kebijakan}

Berdasarkan hasil penelitian yang dilakukan melalui wawancara mendalam dan observasi secara langsung ditemukan bahwa Kebijakan sesuai dengan Peraturan Pemerintah Nomor 33 tahun 2012 pasal 5 mengatur tanggungjawab pemerintah daerah kabupaten/kota yang ada di Indonesia dalam pelaksanaan program ASI eksklusif dengan memberikan konseling penerapan IMD dan ASI eksklusif dari petugas kesehatan setiap posyandu untuk ibu hamil.

\section{Tenaga Kesehatan}

Berdasarkan hasil penelitian yang dilakukan melalui wawancara mendalam dan observasi secara langsung ditemukan bahwa ibu hamil sudah mendapatkan informasi tentang manfaat IMD dan ASI eksklusif, dan juga sudah mengetahui tata cara menyusui yang benar, kendala ibu hamil setelah melahirkan terkadang tinggal bersama keluarga maka bayinya sebelum usia 6 bulan sudah diberikan susu formula, keluarga ada yang tidak mengetahui manfaat dari ASI eksklusif, hal inilah yang menjadikan program ASI tidak tercapai

\section{Sarana dan Prasarana}

Berdasarkan hasil penelitian yang dilakukan melalui wawancara mendalam dan observasi secara langsung terkait sarana prasarana di Puskesmas ini sudah cukup, tetapi masih membutuhkan laptop dan LCD untuk mempermudah tenaga kesehatan dalam menyampaikan penyuluhan

\section{PEMBAHASAN}

\section{Kebijakan}

ASI Ekslusif adalah air susu ibu yang wajib diberikan atau disusukan pada bayinya yang baru lahir sampai bayinya berusia 6 bulan, tanpa diberikan tambahan apapun pada bayi tersebut. Dimana selama pemberian ASI Ekslusif, ibu tidak perlu 
memberikan tambahan makanan apapun pada bayinya, baik air putih, sari buah, maupun susu formula. Selama 6 bulan pertama bayi, benar-benar hanya mendapatkan air susu ibu saja (Widuri, 2013)

Kebijakan merupakan sekumpulan peraturan yang dibuat oleh pihak yang berwenang dalam kebijakan yang terdapat pada PP NO. 33 tahun 2012 yang bertujuan untuk menjamin pemenuhan hak bayi untuk mendapatkan ASI Eksklusif hingga 6 bulan, memberikan perlindungan kepada ibu dalam memberikan ASI eksklusif kepada bayinya, meningkatkan peran dan dukungan keluarga, masyarakat, Pemerintah Daerah, dan pemerintah terhadap pemberian ASI eksklusif.

Kebijakan program ASI Ekslusif adalah program yang di buat oleh pemerintah untuk meningkatkan kesejahteraan kesehatan ibu dan anak. Dengan adanya program ini pemerintah dapat mengetahui cakupan pemberian ASI disetiap daerah (Jones, 2017).

Penelitian ini sejalan dengan penelitian yang dilakukan oleh Afriany dkk (2017), bahwa sebenarnya menyusui, khususnya yang secara eksklusif merupakan cara pemberian makan bayi yang alamiah. Namun, seringkali ibu-ibu kurang mendapatkan informasi bahkan seringkali mendapatkan informasi yang salah tentang manfaat (ASI) eksklusif, tentang bagaimana cara menyusui yang benar, dan apa yang harus dilakukan bila timbul kesukaran dalam menyusui bayi, hal ini terjadi karena ibu hamil tidak mendapatkan informasi yang akurat dari tenaga kesehatan tentang manfaat ASI eksklusif.

Berdasarkan hasil penelitian dan teori, maka peneliti berpendapat bahwa kebijakan tentang program ASI eksklusif yang dibuat oleh Peraturan Pemerintah Nomor 33 tahun 2012 pasal 5 tentang ASI eksklusif harus disampaikan ke Bidan dan memberikan pelatihan tentang ASI eksklusif dan bidan menyampaikan kepada ibu hamil. Dalam program ini bertujuan untuk tercapainya cakupan ASI eksklusif, dengan demikian antara bidan sebagai tenaga kesehatan serta kader saling bekerjasama agar bisa ibu hamil melaksanakan ASI ekslusif dan mendapatkan IMD ketika anaknya lahir.

\section{Tenaga Kesehatan}

Menurut Undang-undang RI Nomor 36 Tahun 2014, tenaga kesehatan adalah setiap orang yang mengabadikan diri dalam bidang kesehatan serta memiliki pengetahuan dan atau keterampilan melalui pendidikan dibidang kesehatan untuk jenis tertentu memerlukan kewenangan untuk melakukan pelayanan kesehatan.

Berdasarkan PP ASI Nomor 33 tahun 2012 ASI informasi dan edukasi yang harus disampaikan oleh Tenaga Kesehatan kepada ibu hamil mengenai: keuntungan dan keunggulan pemberian ASI, gizi ibu, persiapan dan mempertahankan menyusui, akibat negatif dari pemberian makanan botol secara parsial terhadap pemberian ASI dan kesulitan untuk mengubah keputusan untuk tidak memberikan ASI.

Dalam penelitian Hidayah (2016) menyatakan bahwa tenaga kesehatan harus terjun langsung untuk penambahan ilmu pengetahuan bagi dukun beranak agar disaat membantu kelangsungan kelahiran dukun bisa dan mampu menyampaikan arti penting ASI Eksklusif kepada ibu yang baru melahirkan, karena masih banyak masyarakat yang membantu kelangsungan kelahiran dengan dukun beranak. Maka dari itu jika dukun beranak pengetahuan akan arti penting menyusui secara Eksklusif masih awam maka upaya pelaksanaan program ASI Eksklusif sulit tercapai dengan baik.

Berdasarkan hasil penelitian dan teori, maka peneliti berpendapat dengan adanya tenaga kesehatan dan bekerjasama serta koordinasi dengan instansi terkait 
besar harapan pencapaian cakupan ASI Eksklusif di Puskesmas Alai khususnya dan desa-desa lain umumnya mengalami peningkatan secara signifikan. Meskipun puskesmas pelayanan kesehatan yang sederhana namun akan menjadi sangat penting dan berarti bagi masyarakat jika keberadaannya benar-benar dirasakan oleh masyarakat, bagitu pun dengan pelayanan yang memuaskan masyarakat, dalam hal ini pendekatan antara bidan hamil ini bisa memicu dalam tercapainya program ASI eksklusif

\section{Sarana dan Prasarana}

Ketersediaan sarana dan prasarana yang diperlukan untuk menunjang terjadinya suatu perilaku kesehatan. Keterampilan yang dimaksud yakni misalnya keterampilan tenaga kesehatan, sedangkan untuk sarana dan prasarana misalnya fasilitas pelayanan kesehatan, keterjangkauan biaya dan jarak untuk mengakses fasilitas pelayanan kesehatan tersebut, jam operasional pelayanan kesehatan, ketersediaan fasilitas menyususi, lama meninggalkan bayi dan lain-lain (Akib, 2017)

Menurut PERMENKES RI Nomor 15 Tahun 2013 (pasal 1 ayat 3), mengatakan bahwa ruangan yang dilengkapi dengan prasarana untuk menyusui bayi, memerah ASI, menyimpan ASI perah, dan atau konseling menyusui atau ASI disebut dengan fasilitas khusus menyusui dan atau memerah ASI yang dikenal sebagai ruang laktasi. Diadakannya ruang laktasi ini bertujuan untuk memberikan perlindungan tidak hanya kepada ibu supaya dapat memberikan ASI eksklusif namun juga bagi hak anak guna mendapatkan ASI eksklusif.

Menurut penelitian Widyastuti dkk (2017), dalam mengimplementasikan berbagai macam program baiknya didukung dengan sarana dan prasarana yang memadai sehingga pencapaian target bisa terpenuhi dengan baik, karena tanpa adanya sarana dan prasarana merupakan hal yang sangat penting untuk menunjang pelaksanan pelayanan kesehatan, misalnya penyediaan perlengkapan posyandu dan fasilitas yang dapat digunakan sebagai tempat kegiatan konseling bagi ibu menyusui, tersedianya tempat untuk posyandu, konseling atau pun penyuluhan dan tempat pertemuan bagi ibu-ibu menyusui serta berbagi cerita dan pengalaman sehingga bertambah pengetahuan tentang arti penting ASI Eksklusif.

Berdasarkan hasil penelitian dan teori, maka peneliti berpendapat dalam hal pengadaan sarana dan prasarana yang memadai pihak puskesmas telah melakukan koordinasi dengan Dinas Kesehatan Meranti, agar sarana dan prasarana penunjang pelaksanaan kegiatan program ASI eksklusif di puskesmas Alai segera dipenuhi. Apabila sarana dan prasarana tidak memadai maka pencapaian cakupan ASI Eksklusif yang dicanangkan oleh dinas kesehatan sulit tercapai karena kekurangan sarana dan prasarana penunjang pelaksanaan program ASI Eksklusif tersebut. Begitu juga dalam penyediaan perlengkapan posyandu dan fasilitas yang dapat digunakan sebagai tempat kegiatan konseling bagi ibu menyusui, tersedianya tempat untuk posyandu, konseling atau pun penyuluhan dan tempat pertemuan bagi ibu-ibu menyusui serta berbagi cerita dan pengalaman sehingga bertambah pengetahuan tentang arti penting ASI Eksklusif.

\section{KESIMPULAN}

Kebijakan dalam bentuk memberikan konseling pada ibu hamil untuk melakukan IMD dan eksklusif pada bayinya serta serta kebijakan dalam memberikan penyuluhan terus menerus untuk ibu hamil, Tenaga kesehatan berperan penting dalam menjalankan program ASI Eksklusif, dimana tenaga kesehatan ini paling penting dalam pendekatan dengan ibu hamil agar 
tercapai program ASI eksklusif. Sarana prasarana di Puskesmas ini sudah cukup baik, tetapi ada beberapa yang belum ada seperti laptop dan LCD untuk menampilkan video tata cara menyusui yang benar

\section{DAFTAR PUSTAKA}

Afriany,F., Widyastuti, I., Juniarsih, D., \& Abrina, D. E. S. (2017). Implementasi Program ASI Eksklusif Dalam Meningkatkan Kesehatan Bayi (Studi Pada Puskesmas Pembantu (Pustu) Desa Sarimulya Kecamatan Rimbo Ilir). Jurnal Administrasi Sosial dan Humaniora (JASIORA), Vol. $\quad 2 \quad$ No. 3 (http://jurnal.stiasetihsetiomb.ac.id/i ndex.php/admngr/index). Diakses 15 Maret 2020.

Astusti, S. (2016). Pengaruh Pelatihan Pemberian ASI Eksklusif Terhadap Pengetahuan Menyusui Kelompok Pendukung ASI di Desa Sumedang. Jurnal Kesehatan Masyarakat. Vol.01 No.03. Diakses 6 Februari 2020.

Ayuningtyas, D. (2014). Kebijakan Kesehatan: Prinsip dan Paraktik. Raja Grafindo Perkasa: Jakarta

Balitbangkes Kemenkes RI.(2010). Laporan Riset Kesehatan Dasar (Riskesdas). Jakarta.

Balitbangkes Kemenkes RI.(2013). Laporan Riset Kesehatan Dasar (Riskesdas). Jakarta.

Dewi, A., Suparwati, A., \& Suryawati, C. (2013). Analisis Implementasi Kebijakan ASI Eksklusif Di Tingkat Kabupaten Kebumen. Jurnal Kesehatan Masyarakat. Vol 2 no (1). Dikases 10 Februari.

Departemen Kesehatan RI. (2015). Manajemen Laktasi Buku Panduan Bagi Bidan dan Petugas Kesehatan di Puskesmas. Jakarta: Direktorat Jendral Bina Kesehatan Masyarakat.
Departemen Kesehatan RI.(2016). Managemen Laktasi. Jakarta: Direktorat Jendral Bina Kesehatan Masyarakat

Departemen Kesehatan RI.(2017). Pedoman Penyelenggaraan Pelatihan Konseling Menyusui Dan Pelatihan Fasilitator Konseling Menyusui. Jakarta: Direktorat Jendral Bina Kesehatan Masyarakat

Durlak, J.A., \& DuPre, E. P. (2018). Implementation Matters: A Review of Research on the Influence of Implementation on Program Outcomes and the Factors Affecting Implementation. Jurnal Community Psychol, Vol 01 no 2. Diakses 6 Februari 2020.

Dwi, A. R. (20198). Implementasi Program ASI Eksklusif di Wilayah Kerja Puskesmas Aek Songsongan Kecamatan Aek Songsongan Fakultas Kesehatan Masyarakat Universitas Sumatera Utara Kabupaten Asahan. Jurnal Professional FIS UNIVED Vol. 4 No. 1. http://repositori.usu.ac. id/handle/123456789/5923. Diakses 11 Februari 2020.

Februhartanty, T. (2018). Gambaran Pemberian ASI Ekslusif Bayi 0-6 Bulan di Wilayah Kerja Puskesmas Samigaluh II. Jurnal Kesehatan Reproduksi. Vol.02:81-89. Diakses 4 Februari 2020.

Profil Puskesmas Alai. (2020). Kecamatan Tebing Tinggi Barat Kabupaten Kepulauan Meranti

Fikawati, S., \& Syafiq, A. (2019). Praktik Pemberian ASI Eksklusif, PenyebabPenyebab Keberhasilan dan Kegagalannya. Jurnal Kesmas Nasional. Vol; 4 No (3). Diakses 5 Februari 2020.

Hendarto, A \& Pringgadini, K. (2018). Bedah ASI. Jakarta : Balai Penerbit FKUI.

Kusumanegara, S. (2010). Ilmu Kebidanan, Kandungan dan KB. Jakarta : EGC 
Prasetyono, D. S. (2019). ASI Eksklusif. Yogyakarta: Diva Press.

Peraturan Pemerintah Republik Indonesia Nomor 33. (2012). Pemberian Air Susu Ibu Eksklusif. Jakarta.

Riyadi, M. W. (2015). Pedoman Klinis Pediatri. Jakarta: EGC.

Roesli, U. (2015). Mengenal Asi Eksklusif. Jakarta: Trubus Agriwidya.

Suradi, R. (2018). Manfaat ASI dan Menyusui. Jakarta: Balai Penerbit FKUI. 